Article

\title{
Examining the Collocational Knowledge of Libyan Arabic-Speaking Learners of English in Different Learning Environments: Classroom Learning vs. Naturalistic Learning
}

\author{
Carima Awaj \\ Department of English Language, Al-Mergheb University, Al Khums, Libya; ca_20063@yahoo.com; \\ Tel.: +218-92-748-6349
}

Received: 14 November 2017; Accepted: 26 April 2018; Published: 7 May 2018

Abstract: The recognition that collocation is an important, yet challenging, variable in second language development has attracted extensive research into how to enhance collocation learning. This study examines the collocational knowledge of Libyan Arabic-speaking learners of English by focusing on the influence of two main factors, the learning environment and the native language (L1), since it has been claimed that these factors affect L2 collocation development. Unlike previous studies on collocations which have largely focused on testing classroom learners, this study compares the use of English collocations by both naturalistic learners and classroom learners to explore which learning environment enhances collocation development more. Thirty-six Libyan learners participated in this study (18 formal classroom learners and 18 informal naturalistic learners); they were asked to complete production and reception tests of English collocations. A questionnaire and a vocabulary recognition task (VRT) were additionally used to facilitate interpretation of the data, by eliciting information about learners' degrees of exposure to informal, naturalistic English and their knowledge of the individual words in collocations. The results showed that collocations are a problematic aspect of language for all L2 learners in the study. However, a naturalistic setting was found to provide a better learning environment for collocation development than a classroom setting. Additionally, the native language of the learner was also found to have an effect on their L2 collocational knowledge. This influence had more of a positive effect on naturalistic learners' knowledge, and a more negative effect on classroom learners' knowledge. The findings also revealed a strong correlation between learners' collocational knowledge and their amount of exposure to informal, naturalistic English.

Keywords: collocations; language transfer; classroom learning; naturalistic learning; language exposure

\section{Introduction}

\subsection{Background Research}

Earlier methodologies of language teaching were largely focused on grammar and disregarded the importance of vocabulary learning and teaching in second language development. Richards (1976, p. 77) states that "the teaching and learning of vocabulary has never aroused the same degree of interest within language teaching as have such issues as grammatical competence, contrastive analysis, reading, or writing, which have received considerable attention from scholars and teachers". Later, there was more recognition that grammar and vocabulary are both indispensable aspects of knowledge that second language (L2) learners need to master (Morra and Camba 2009). Wilkins (1972, p. 10) went further to argue that vocabulary learning is an essential element in language acquisition, as "without grammar little can be conveyed, without vocabulary nothing can be conveyed". 
Within the area of vocabulary studies, special attention has been given to the study of formulaic language since it represents a large part of discourse (Erman and Warren 2000) and because it distinguishes the speech of native and non-native speakers (Conklin and Schmitt 2007). Wray (2002, p. 9) defines formulaic language as "a sequence of words which is prefabricated: that is, stored and retrieved whole from memory at the time of use, rather than being subject to generation or analysis by the language grammar". In formulaic language publications, collocations have received greater attention due to the increased recognition that collocations are "an important organising principle in the vocabulary of any language" and because "knowledge of collocational appropriacy is part of the native speaker's competence" (McCarthy 1990, pp. 12-13). Due to this importance, many researchers have investigated the roles of collocations and formulaic language in developing second language fluency and idiomaticity (Hoey 2005; Lewis 2000; McCarthy 1990; Schmitt 2004; Wray 2002).

However, despite the extensive research on collocations in second language literature, the development of L2 collocational knowledge is still found to be challenging for non-native speakers. This could be attributed to the fact that most collocation studies have tested learners with similar learning experiences (classroom teaching) and that collocations have not received much attention from teachers in classrooms (particularly in Arabic-speaking countries). In the latter case, learners are likely to rely on their L1 collocational knowledge when facing difficulties in producing L2 collocations.

\subsection{Research Focus}

This study will examine the productive and receptive collocational knowledge of Libyan Arabic-speaking learners of English who have learnt English formally only through classroom instruction in an EFL (English Foreign Language) environment (English learners in Libya), and those who have learnt the majority of their English informally through exposure to other native English speakers in a native English speaking environment (Libyan learners in UK), to investigate the role played by L1 and the learning environment on collocation development.

The initial understanding of the concept "learning environment" was initially very broad, but in the process of conducting this project, it has emerged that an important factor to help distinguish between different learning environments is the type of learning input that the learners receive. For example, in a classroom setting the input is manipulated to contain the linguistic features that are targets of instruction, whereas, the input in a naturalistic setting is unstructured, with the main emphasis being on communication. However, even though the naturalistic learners ${ }^{1}$ had studied English as a single subject at schools in their home country, it was not expected for them to have learnt collocations at that early stage of learning given that none of the learners were English major students, and because collocations are believed to be a complicated language aspect that is usually learnt at advanced stages of learning (McCarthy 1990). Therefore, it was believed that the naturalistic learners had developed their collocation knowledge informally while being in contact with native speakers in a native-speaking environment.

\subsection{Research Aims and Objectives}

This study has two main aims: firstly, to establish which type of learning helps to enhance learners' knowledge of English collocations the most; and secondly, to investigate whether Arabic (the learners' L1) has an effect on the learners' collocational knowledge, and if so, to determine the nature of that effect. This investigation is important for two key reasons. First of all, most of the previous studies that have investigated the collocational knowledge of Arab learners have been conducted only with classroom learners (e.g., Al-Zahrani 1998; Farghal and Obiedat 1995; Hussein 1990), and there has not

1 The term "naturalistic learning" is used in this study to refer to the informal learning setting in which L2 learners are exposed to language through direct contact with native speakers at home or at work in English native environments, without being formally taught in structured classrooms. 
been much focus on the development of collocation knowledge in informal, naturalistic settings by Arabic-speaking learners of English. Ergo, the current study will compare the performances of learners in both types of English learning settings on two different categories of English collocations. Secondly, the influence of L1 on collocation use has been attested by many studies (e.g., Biskup 1992; Granger 1998; Nesselhauf 2003). Therefore, it is worth examining if having Arabic (Libyan Arabic) as L1 will help or hinder the acquisition of English collocations. The other sub-objective of the study is, since the current findings in literature are contradictory, to identify whether the reception or the production of collocations is more challenging for learners.

\subsection{The Value of This Research}

This study is significant because most studies involving the contributions of formal classroom instruction vs. informal naturalistic learning to SLA (Second Language Acquisition) have focused on investigating the grammatical accuracy of adult L2 learners (e.g., Krashen and Seliger 1975; Perkins and Larsen-Freeman 1975; Pica 1983; Turner 1979). As well as this, most studies that have examined L2 collocational knowledge have been carried out on classroom learners (either in EFL, or ESL, English Second Language, contexts). This study is an attempt to bridge some of the gaps in the existing literature by investigating the roles played by different conditions of exposure to the target language (controlled formal instruction vs. free naturalistic exposure) on lexical development, particularly collocational development. The findings of this study will also be considered for pedagogical decisions about collocations teaching in the future.

\section{A Review of Literature on Collocation}

This review addresses some of the key issues surrounding L2 collocations from the perspective of the learning environment and L1 influence. Firstly, a preliminary account of what "collocations" are, and how they have been categorised must be discussed.

\subsection{Definition of the Term "Collocation"}

Despite the extensive research on collocations in linguistics and language teaching, the term "collocation" is still far from being well-defined. According to Nesselhauf, the only trait common to the diverse uses of the term is that they refer to "some kind of syntagmatic relation of words" (Nesselhauf 2005, p. 11). For example, Baker (1992) defines collocations as the tendency for some words to occur frequently in language, and for Lewis (1997, p. 44), "collocations are those combinations of words which occur naturally with greater than random frequency. Collocations co-occur, but not all words which co-occur, are collocations". Clearly, Lewis (1997) definition shows some awareness that it is not only the co-occurrence that characterises collocations. The lack of a definite description of the term is believed to be because researchers have approached the study of collocations from different angles. Nevertheless, the two major approaches to collocation studies are the "frequency-based approach" and the "phraseological approach". Although both approaches adopt a cognitive view of language, they differ in their definitions of collocations.

\subsubsection{Frequency-Based Approach}

The frequency-based tradition was first established by Firth (1957, p. 183), who used the term in a way that is reminiscent of present day use: he believed that collocations are mainly about "the company that words keep" and that collocations represent the way in which a word's meaning can be obtained. Firth (1957) theory on lexical meaning was then developed by other linguists (known as Neo-Firthians), such as Halliday (1966) and Sinclair (1966), who similarly emphasised the importance of the co-occurrence of collocations. For them, a word combination is only considered to be a collocation if the frequency of co-occurrence of its lexical items is statistically significant and within a certain distance in the sentence. In his attempt to delimit this distance, Sinclair (1991, p. 170) argued that "the usual measure of proximity is a maximum of four words intervening". 


\subsubsection{Phraseological-Based Approach}

On the other hand, the treatment of collocations in the phraseological approach has been strongly influenced by Russian phraseology. Collocations are viewed as "a type of word combination, most commonly as one that is fixed to some degree but not completely" (Nesselhauf 2005, p. 12). Unlike the frequency-based approach, the definition of collocation is based on its delimitation from other kinds of word combinations, namely idioms and free combinations. However, the distinction between collocations and free combinations relies on whether the substitution of lexical items is arbitrary or motivated by semantic commutability. For Cowie $(1981,1994)$, the substitutability of lexical items in free combinations is based on semantic features; for example, in drink tea, the object can be substituted by any noun containing the semantic feature [+LIQUID]. Conversely, with collocations, the substitutability of lexical items is arbitrary and hence, cannot be semantically oriented, as in substituting the verb perform with do or make, which results in violations such as *make/do a task.

The distinction between collocations and idioms, however, is based on semantic transparencywhether the meaning of the word combinations is semantically transparent. With collocations, at least one lexical element has to have a literal meaning, whereas the meaning of idioms is characterised as "non-literal" and "non-compositional" (Cowie 1981, 1994; Hausmann 1989). Additionally, in this approach, one lexical item of collocation is semantically autonomous, while the other is semantically dependent; for example, in do favour, favour is autonomous which, in turn, determines the dependent element do rather than *take or *make (Mel'čuk 1998).

\subsection{Classifications of Collocations}

Given that scholars have approached the study of collocations differently, it is unsurprising that there is not yet an agreement on the classification of the term. While some authors (e.g., Benson et al. 1986; Hill 2000; Lewis 2000) adopt a phraseological approach in their classifications, others (e.g., Halliday 1966) take a frequency-oriented classification. Authors such as Nation and Herbst, however, show elements of both in their classifications (Herbst 1996; Nation 2001). Despite this, the criteria that most researchers argue for are semantic transparency, degree of substitutability, and the degree of productivity (Howarth 1998; Nattinger and Decarrico 1992). Hence, if word combinations were placed on a continuum based on these criteria, on one end of the collocational continuum would be free collocations, since they are highly productive, semantically transparent, and easily substitutable, whereas idioms would be on the other end, since they least frequently contain the aforementioned criteria. Restricted collocations are considered to be between these two extremes of the continuum (Huang 2001).

\subsection{Collocations in This Study}

This study targets combinations that are fixed to some extent, and in which at least one of the lexical elements has a literal meaning; thus, it adopts a phraseological rather than a frequency-based definition of collocation, meaning that it treats collocation as a type of combination (Cowie 1994) rather than the frequency of co-occurrence of words in a certain span (Sinclair 1991). However, since a clear, non-controversial classification of collocation does not yet exist, this study will adopt Benson et al. (1986) classification and Howarth (1998) categorisation model of lexical collocation, since they are phraseological in nature and they clearly distinguish lexical collocations, in particular, restricted collocations (which are the targets of this study) from other kinds of word combinations. Benson et al made a distinction between lexical and grammatical collocations, as the former entails the combination of two lexical items (e.g., verb and noun), whereas grammatical collocations involve combining a lexical item with a grammatical one (e.g., adjective and preposition).

Howarth (1998) goes further and classifies lexical collocations into four categories: free combinations (those that are easily substituted, the meaning of which can be deduced from the literal meaning of its constituents, e.g., blow a trumpet); restricted combinations (those that are more limited in the 
number of collocating elements, the use of which is restricted to a particular context, e.g., blow a fuse); figurative idioms (those that have a metaphorical meaning which can somehow be understood from their literal meanings, e.g., blow your own trumpet), and pure idioms (those with an unpredictable meaning, e.g., blow the gaff). Of particular importance to this study are restricted combinations.

\subsection{The Importance of Collocation Learning}

The claim that collocation learning promotes natural language use has been supported by many scholars (e.g., Hymes 1972; Pawley and Syder 1983) on the grounds that choosing the most natural option from a variety of grammatical possible ways of saying something cannot be resolved by grammatical competence. For example, although both tall and high describe height, it is possible to say high/tall building and tall boy but not *high boy, which makes it deficient to merely rely on grammatical rules to predict possible combinations in certain contexts (Lewis 2002). Instead, this requires knowledge of strings of language that are recognised as fixed expressions in native speech. Subsequently, there has been more recognition among researchers that "collocational competence" is one of the factors distinguishing native from non-native speakers (Lewis 2000). Furthermore, Lewis argues that improving the collocational knowledge of EFL learners can help them move across an "intermediate plateau" and become advanced learners, especially as there is evidence (e.g., Pawley and Syder 1983) that human brains are better at memorising than at processing (Lewis 2000). Hence, having large number of pre-fabricated units stored reduces processing effort which, in turn, improves L2 fluency. Moreover, knowledge of collocations has also been found to promote comprehension, since learners are more driven towards comprehending lexical phrases as unanalysed wholes, rather than as individual words (Brown 1974; Hunston and Francis 2000).

\subsection{Collocation and Language Teaching}

However, the lack of a systematic method of teaching collocations may have caused some problems for L2 learners, since they might not have the sufficient cognitive ability (especially at early stages of learning) to recognise how words are conventionally combined in the target language (Wray 2002). Howarth (1998) goes further and argues that learners' failure to understand collocational patterns may even lead to a complete avoidance of them in L2 production. For this, there is a consensus among scholars (e.g., Cowie 1988; Lewis 1993; McCarthy 1990; Howarth 1998) that collocations should occupy an essential place in classroom teaching and materials. However, a coherent methodology of teaching collocations has not yet been developed. In recent years, some approaches (e.g., Willis' (1990) Lexical Syllabus, Lewis (1993) Lexical Approach) have been developed that place a central focus on teaching prefabs; such approaches, however, "are based on the analysis of native speaker prefabs and none ... is based on any systematic observation of prefab in learner language" (Nesselhauf 2005, p. 3). Thus, a more coherent methodology that considers learners' difficulties with collocations is still required.

Nevertheless, some researchers have made pedagogical suggestions based on their empirical findings. Granger, for example, suggests teaching collocations that are different in L1 and L2 as she found that French learners correctly produced collocations that have equivalents in their L1 (Granger 1998). For Granger, "directly translatable" collocations can be appropriately transferred to L2, but for collocations with no direct translation equivalents, direct teaching is necessary (Schmitt 2000). Likewise, Vasiljevic (2008, p. 3) asserted the importance of explicit teaching of non-congruent collocations by arguing that any clash between L1 and L2 collocational differences and the acquisitioned collocation in L2 can hinder the acquisition processes and might "even lead to lexical fossilization". A similar emphasis was placed on teaching non-congruent collocations by Al-Zahrani (1998); Bahns (1993); and Nesselhauf (2005) based on their own research findings. Thus, it is widely recognised that collocations are a problematic, yet important, aspect of L2 learning, which has attracted considerable attention in SLA research. 


\subsection{Previous Studies on Collocations in Learner English}

There has been much research on collocations, some which has focused on the theoretical issues behind collocational competence (e.g., Allerton 1984; Howarth 1998), some on memorisation and fluency (e.g., Al-Zahrani 1998; Brown 1974), some on collocation knowledge and vocabulary size (e.g., Mochizuki 2002), some on the influence of L1 (e.g., Biskup 1992; Granger 1998; Hussein 1990; Mahmoud 2005; Nesselhauf 2003), some on the need for collocation learning (e.g., Bahns 1993; Bahns and Eldaw 1993; Laufer 1990; Lennon 1996), and some on the learner's use of collocations (e.g., Farghal and Obiedat 1995; Zughoul 1991). However, the discussed studies here will be grouped according to the kind of learning involved in collocation development. Relevant studies on the influence of L1 on collocation learning will be discussed under the classroom learning section, as they were only conducted on classroom learners and not on naturalistic learners.

\subsubsection{Classroom Learning}

The studies considered in this paper were conducted on classroom learners, the majority in EFL environments (e.g., Bahns and Eldaw 1993; Biskup 1992; Brown 1974; Farghal and Obiedat 1995; Huang 2001; Hussein 1990; Marton 1977; Martynska 2004), with some in ESL environments (e.g., Bonk 2000; Cowie and Howarth 1996; Dechert and Lennon 1989; Lennon 1996; Zhang 1993). Bahns and Eldaw (1993), for example, tested the productive collocational knowledge of 58 advanced German learners of English on 15 verb-noun collocations. The participants were grouped into two sets: one group took a German to English translation test, and the other group took a format test in which the target collocations were put into English sentences, with the verb collocating with the missing noun. They found the verbs that were part of collocations were difficult to translate.

In another study, Farghal and Obiedat (1995) tested the collocational knowledge of 57 Arabic university students. Group 1 completed a fill-in-the-blank test while Group 2 completed a translation test. The results revealed very poor knowledge of English collocations (18\% for Group 1 and 5\% for Group 2). In their analysis, Farghal and Obiedat (1995) found that the participants adopted four lexical simplification strategies while dealing with the tests: synonymy, avoidance, L1 interpretations, and paraphrasing. Synonymy was the most frequently adopted strategy among the two groups $(41 \%$ and $35 \%)$ while avoidance was the second most adopted strategy (27\% and $21 \%)$. The percentages of L1 transfer and paraphrasing were not high $(9.9 \%$ and $12.6 \%$, and $3.8 \%$ and $25.1 \%$ respectively), which meant that the influence of L1 was very limited to German learners. The high use of synonymy, however, was perceived as a direct result of collocation unawareness.

Both of the aforementioned studies tested only the productive knowledge of collocations, probably due to the influence of earlier findings (e.g., Biskup 1990; Marton 1977) that learners comprehend more than they are able to produce. Therefore, this study will test both receptive and productive knowledge to examine if the findings support these earlier claims. These previous studies also differ from this study in how the collocational knowledge was compared. While previous studies compared the performances of different groups on different tests, this study will compare the performance of different groups (of the same L1) on the same test items and instruments. This should make the sample more homogeneous for determining whether the learning environment and L1 affect the learner's collocations. Additionally, this paper targets participants with different experience levels in learning collocations (naturalistic vs. classroom); whereas the previously discussed studies only targeted a single learning environment (classroom).

\section{Collocational Development and L1 Influence}

Within the classroom studies, some researchers (e.g., Biskup 1992; Granger 1998; Nesselhauf 2003) carried out studies solely to test the influence of L1. Hussein, for example, tested 200 Jordanian students and found that L1 (Arabic) led learners to produce some correct and incorrect collocations in English. The correct answers were mainly limited to either lexical items that are frequent in English, or those 
which had Arabic equivalents (Hussein 1990). Similarly, Nesselhauf (2005) studied the use of verb-noun collocations by German learners and found that nearly two-thirds of the produced collocations were acceptable, while one-third were unacceptable. Nesselhauf (2005) stated that among the many factors that affected the learners' acquisition of verb-noun collocations were the degree of restrictions of collocations, the congruence of collocations in L1 and L2 (i.e., a word-for-word translation equivalent in L1), and the learners' exposure to L2. These last two factors are crucial to this study, since Nesselhauf claims that non-congruent collocations cause more problems for learners; hence, they deserve more attention during teaching, and as "a prolonged stay in an English-speaking country [ ... ] can enable learners to become more native-like in their judgments of frequent collocations than learners without any L2 natural exposure" (Schmitt 2008, p. 448). Thus, it is worth checking if these claims are applicable for Arabic-speaking learners.

However, all of the discussed studies have examined the classroom learner's knowledge of collocations, but without giving a clear picture of the kind of teaching practices adopted. Thus, it is not clear whether it is the lack of explicit teaching and awareness of collocations or the lack of immersion with a comprehensible input that has contributed to the poor collocational knowledge of the learners. Having said this, the poor performance of classroom learners may bring to light the effectiveness of natural informal learning for better collocation development.

\subsubsection{Naturalistic Learning}

The majority of studies on collocations have been done on classroom learners; no work, to my knowledge, has compared the collocational knowledge of classroom and naturalistic learners. Most of the comparison studies between classroom and naturalistic learning have focused on grammar (e.g., Krashen et al. 1976; Krashen et al. 1978; Pica 1983). Therefore, a clear shortcoming in previous classroom learning studies is that the majority were testing the product of learning without relating it to the nature of the input involved in that learning, and how it might have affected their learning product. A few other studies (e.g., Schmitt 2008; Siyanova and Schmitt 2008; Wray 2002) have given an account on how language knowledge might have been influenced by the nature of input. Wray (2002), for example, argued that adult L2 learners do not retain information about collocations they encounter in input, because their mature cognitive system and the nature of their learning situations push them towards a word-focused approach of learning She justified this by claiming that collocations can only be learnt if they are present in the input of language; and since there is no reason to believe that the learners' input has been simplified in regard to collocational content, the absence of collocations in the learners' output indicates that adult learners are incapable of learning collocations implicitly through exposure. She further adds that, unlike first language learners who acquire language as whole strings, L2 learners are hypothesised to start from small units and then gradually move to bigger strings. This could negatively affect their collocational development as learners are likely to "home in on the individual words, and throw away [ ... ] what they occurred with" (Wray 2002, p. 206).

In contrast to Wray (2002); Schmitt (2008, p. 334) argues that collocations are better learnt through "massive exposure to the L2". For him, the contextualised nature of collocations implies that implicit learning is the best approach to enhance its development. Similarly, Siyanova and Schmitt (2008) contradict Wray (2002) model by claiming that L2 learners have been found to be sensitive to the patterns of co-occurrence frequencies; in their study, learners who had spent the longest time in English-speaking environments were the only learners who successfully distinguished medium to high frequency combinations. Other studies (e.g., Durrant and Schmitt 2010), however, have used lab-based experiments to test learners' retention of collocations they were exposed to in a controlled input during a lab training session. The findings were that "adult second language learners do retain information about what words appear together in their input" (Ibid., p. 163). However, these studies again only focused on naturalistic learning of collocations, without relating or comparing it to classroom learning. Thus, this study will compare classroom and naturalistic learners to investigate which environment provides a richer source for collocation mastery. 


\subsection{The Role of Classroom vs. Naturalistic Input in Second Language Acquisition}

Classroom and naturalistic settings are believed to contribute differently to how adult L2 learners internalise the rules of a second language. Krashen (1976) argues that a clear distinction should be made between "learning" and "acquisition", as learners who are taught formally in classrooms will only "learn" the language but will be incapable of acquiring it. "Acquisition", on the other hand, is the process involved in unconscious naturalistic learning. He also adds, in his The Input Hypothesis (Krashen 1985), that learners can benefit from input that is just above their current level of language (i.e., $i+1)$. Thus, for learners to acquire collocations present in the input, the nature of that input has to be just one step ahead their interlanguage level. However, it was not possible to test or even control this in this study, since knowing the learners' current levels was not feasible, particularly for the informal naturalistic group learners. However, this could indicate that the poor collocational knowledge of some naturalistic learners is due to the exposed input being more advanced than their current language level. Therefore, to determine the effect of the learning setting (that is, formal, controlled instruction vs. informal, natural exposure), and the effect of L1 (Arabic) on the collocation knowledge, this study addresses two key research questions:

1. Is there a significant difference between the collocational development of those who learnt English formally in a classroom setting (in an EFL environment) compared to those who acquired the language naturally through informal naturalistic exposure in an English-speaking environment? 2. Is there a significant influence of L1 (Arabic) on the learners' knowledge of English collocation?

By targeting these research questions, it will also be possible to empirically illustrate whether collocations could be learnt incidentally through informal, naturalistic exposure to the native language, and also to test whether it is the similarities or differences between L1 and L2 collocations that cause more problems for Libyan Arab learners of English. Accordingly, our formulated hypotheses are:

Hypothesis 1. Learners in an informal, naturalistic setting will have a better understanding of English collocations than formal classroom learners.

Hypothesis 2. Arabic will have an influence on the participants' knowledge of collocations; this influence will be more problematic for the performance of classroom learners.

\section{Methodology}

\subsection{Participants}

Two groups of adult Libyan Arabic-speaking learners from two different learning environments (formal classroom vs. informal naturalistic) participated in this study. While the first group included 18 final year English major students at Almergeb University, Libya, who had only learnt English through formal instruction, the second group consisted of 18 Libyans in the UK who had learnt most of their English naturally through informal exposure to native speakers' speech. Since it was not possible to determine the language proficiency level of the latter group using formal tests (e.g., IELTS), the decision was made to only include participants who with sufficient previous contact with English so that they had a comparable proficiency in English to that of final year English major students. Accordingly, recruitment was limited to learners who had studied degrees (other than English) in the UK, as lecture input could still be viewed as unstructured, naturalistic input, since it does not teach language rules explicitly, or to those who are in employment, as they should have good communication skills. All naturalistic learners had to have been living in the UK for at least two years, but without ever attending formal English classes during their residence. In this way, nine workers and nine degree holders comprised the naturalistic learners group of this study.

All classroom participants had been studying English as their major for seven years (at secondary school and university), but had never studied English aboard. Those participants were contacted 
and tested, after having the study explained to them, by a colleague who is a linguist and works at the same university. The naturalistic learning group was contacted personally and tested either in individuals or in groups.

\subsection{Materials}

Due to the vast amount of collocations in English, selecting the collocations to be tested was not an easy task. The first decision was to test only lexical collocations and specifically, verb-noun and adjective-noun collocations, as they are claimed to be the most common types of collocations (Channell 1981; Nesselhauf 2003); also, the earlier category "tend to form the communicative core of utterances where the most important information is placed" (Altenberg 1993, p. 227). Afterwards, 20 verb-noun and 20 adjective-noun collocations were selected on the basis of previous studies and by consulting English Collocation in Use-Intermediate (McCarthy and O'Dell 2005) to determine the degree of difficulty of the adopted collocations. Ten collocations from each category were used to test the productive knowledge, and 10 to test the receptive knowledge.

Since one of the study's aims was to test L1 influence, the 10 verb-noun collocations and the 10 adjective-noun collocations of the productive test were further divided into four congruent collocations and six non-congruent collocations. ${ }^{2}$ The assumption was that if L1 is involved in L2 collocational development, then better performance is expected for congruent collocations than for non-congruent collocations, as they have Arabic equivalents and hence, learners can rely on their existing knowledge if they face difficulties. This division was based on a bilingual dictionary, the researcher's knowledge (as a native speaker of Arabic), and a consultation of four other Arabic speakers. Six distracters were added to the production test to determine whether participants were taking the test seriously; they were meant to be very easy work combinations, such as good luck and best wishes. If a participant got more than two of the distracters wrong, their results were omitted from the analysis. In the judgement test, five of the collocations of each category (Verb-Noun and Adjective-Noun) were given in correct combinations, whilst the other five were incorrect.

\subsection{Data Collection}

The data in this study was collected using four elicitation techniques: a questionnaire, a blank-filling test (a production test), an acceptability judgement test (a receptive test), and a vocabulary recognition task (VRT).

\subsubsection{The Instruments}

The questionnaire was adopted from Shehata (2008) with minor modifications, to elicit extra information about the learners' informal, naturalistic exposure to L2. The questionnaire consisted of two sections: the first to collect demographic information about participants' age, gender, time spent learning English etc., while the second reported information about their amount of informal, naturalistic exposure to the target language. The latter was achieved by asking the participants questions regarding the hours they spend daily on watching English programmes, browsing English websites, listening to English songs, making phone calls in English, and speaking and going out with native-speaking friends. All these hours were then calculated as an estimated number for the time each participant spent being exposed to the informal naturalistic language, which, in turn, was considered in the data analysis.

Congruent collocations are English collocations that have direct Arabic equivalents, such as make a decision which corresponds to بصنع قرار yasna3 qarar in Arabic. Non-congruent collocations, however, are English collocations that have no direct Arabic equivalents, such as heavy traffic which corresponds to مرور مزدم morror mozdahem meaning 'crowded traffic' in Arabic. 
The production test, however, was adopted from Farghal and Obiedat (1995) and modified to include 26 sentences (10 verb-noun collocations, 10 adjective-noun collocations, and 6 distracters), where one lexical item of collocations was given and the other was missing. With verb-noun collocations, it was the verb that was missing in all cases, except with 'commit murder'; the noun was missing because the verb is the same in L1 and L2, whereas Arabic allows only for the noun 'crime' but not murder as in English. Therefore, we tested the influence of Arabic on this particular collocation. With adjective-noun collocations, however, it was the adjective that was missing in all sentences apart from two examples, heavy traffic and swift recovery, as more than one adjective can collocate with these nouns. All the collocation categories and distracters were mixed up in the final version of the test.

The acceptability judgment test was adopted from Bonk (2000) and amended to include 20 sentences- 10 sentences on each category of collocations. Since it was not possible to take the two tests in different sessions, it was decided to use different collocation items in the receptive test to eliminate any memorisation effects. Half of the collocations in each category were correct, and the other half were incorrect.

The vocabulary recognition task contained the single lexical items of all collocations used in the study, in addition to 11 nonsense words (e.g., cafens, voking) to monitor and adjust the participants' knowledge (Blum and Levenston 1978). The participants were asked to underline only the words that were familiar to them. From this, it could be decided whether the participants' errors were due to a lack of lexical knowledge, or in the cases where they underlined the single lexical items but produced the wrong collocation, due to being unaware of collocations.

\subsubsection{The Procedure}

All of the data was gathered in one session by giving the participant a consent form to sign, then the questionnaire, followed by the blank-filling test, the judgement test, and finally the VRT. Only the two tests were time-constrained. In order to gain the most authentic data possible, the participants were not informed about the linguistic feature under investigation and the instruction did not specify the kind of word to be put in the gap.

\section{Results}

In this study, there were two independent variables, the influence of the learning environment and the influence of L1 on collocational knowledge; and two dependent variables, the results of the two tests. The independent variables were categorical with two levels each: classroom settings and naturalistic settings for the learning environment variable, and congruent and non-congruent collocations for the L1 influence variable. The dependent variables were also categorical (correct vs. incorrect). To explore the findings, descriptive statistics along with inferential statistics were applied.

\subsection{A Preliminary Analysis of the Naturalistic Group Scores}

Before comparing the two main groups of the study (classroom vs. naturalistic), a preliminary comparison of the two groups of naturalistic learners (workers vs. degree holders) was done to check if it was necessary to keep them distinguished while comparing the whole naturalistic group to the classroom group. Descriptive statistics of the two groups of naturalistic learners are given in Table 1.

It is clear from the above table that there was only a slight variation between the two groups, as workers did slightly better than degree holders in the two tests. To prove this was statistically non-significant, two independent $t$-tests were applied, after checking the distribution of the data was normal, and the findings indicated no significant differences between the two groups on the production test $(t(16)=0.450, p=0.788)$ and on the receptive test $(t(16)=0.248, p=0.823)$. Accordingly, the distinction between the worker and degree holder groups was removed, and they were treated as one group (naturalistic group) in the data analysis. 
Table 1. Mean Scores of Workers and Degree Holders on Production and Reception Tests.

\begin{tabular}{ccccccc}
\hline Group & Category & No. of Participants & Correct & Percentage & Mean & Standard Deviation \\
\hline \multirow{2}{*}{ Degree holders } & Production & 9 & $\begin{array}{c}102 \\
\text { (out of 180) }\end{array}$ & $56.6 \%$ & 11.3333 & 4.35890 \\
\cline { 2 - 6 } Workers & Reception & 9 & $\begin{array}{c}40 \\
\text { (out of 90) }\end{array}$ & $44.4 \%$ & 4.4444 & 2.69774 \\
\cline { 2 - 6 } & Production & 9 & $\begin{array}{r}111 \\
\text { (out of 180) }\end{array}$ & $61.6 \%$ & 12.3333 & 5.04975 \\
\hline
\end{tabular}

\subsection{Results of Collocational Knowledge}

\subsubsection{The Role of the Learning Environment}

The results of the filling-in-the-blank test and the acceptability judgement test of the 36 Libyan learners indicated that some participants had better receptive and productive knowledge of English collocations than others, and that one group did much better than the other in the two tests. Table 2 gives the total correct answers of the individual learners. The number of participants is ordered on the basis of their period of residence in the UK for the naturalistic group, and their self-reported exposure to English for the classroom group, to check if anything interesting was revealed.

Table 2. The Correct Answers from Classroom and Naturalistic Learners on the Two Tests.

\begin{tabular}{ccccc}
\hline \multirow{2}{*}{ No. of Participants } & \multicolumn{2}{c}{ Naturalistic Learners } & \multicolumn{2}{c}{ Classroom Learners } \\
\cline { 2 - 5 } & $\begin{array}{c}\text { Production } \\
\text { (out of 20) }\end{array}$ & $\begin{array}{c}\text { Reception } \\
\text { (out of 10) }\end{array}$ & $\begin{array}{c}\text { Production } \\
\text { (out of 20) }\end{array}$ & $\begin{array}{c}\text { Reception } \\
\text { (out of 10) }\end{array}$ \\
\hline Participant 1 & 19 & 9 & 10 & 6 \\
Participant 2 & 17 & 9 & 8 & 5 \\
Participant 3 & 17 & 7 & 7 & 4 \\
Participant 4 & 18 & 8 & 9 & 3 \\
Participant 5 & 14 & 8 & 8 & 4 \\
Participant 6 & 15 & 7 & 8 & 2 \\
Participant 7 & 15 & 1 & 6 & 4 \\
Participant 8 & 12 & 4 & 5 & 2 \\
Participant 9 & 11 & 5 & 5 & 3 \\
Participant 10 & 10 & 2 & 5 & 1 \\
Participant 11 & 11 & 4 & 5 & 1 \\
Participant 12 & 11 & 2 & 5 & 3 \\
Participant 13 & 10 & 4 & 4 & 2 \\
Participant 14 & 11 & 5 & 4 & 2 \\
Participant 15 & 7 & 2 & 3 & 1 \\
Participant 16 & 9 & 2 & 2 & 2 \\
Participant 17 & 4 & 3 & 3 & 1 \\
Participant 18 & 2 & 1 & 2 & 3 \\
\hline Total & $\mathbf{2 1 3}$ & $\mathbf{8 3}$ & $\mathbf{9 9}$ & $\mathbf{4 9}$ \\
\hline
\end{tabular}

As can be seen from the total scores, the naturalistic learners group had better productive and receptive collocational knowledge than the classroom learners group. Descriptive statistics of the overall results of the two tests are given in Table 3.

The naturalistic learners produced almost twice the amount of correct answers compared to the classroom learners. To compare the statistical significance of the relationship between the two groups (naturalistic vs. classroom) on the two aspects of collocational knowledge (productive vs. receptive), a mixed design ANOVA test was run, after checking that the data was normally distributed. The results indicated a significant main effect caused by the learning environment $(F(1,34)=28.482, p<0.001)$. There was also a significant interaction effect between the knowledge of collocations and the learning environment of participants $(F(1,34)=28.482, p<0.001)$, which indicates that the receptive and the 
productive knowledge of English collocations differed between classroom learners and naturalistic learners. Upon graphing this interaction, it appears that the naturalistic informal group that had better collocational knowledge, and productive knowledge was mastered better than receptive knowledge for both groups. This could be visualized in Figure 1 below.

Table 3. Mean Scores for Productive and Receptive Tests of the Two Groups.

\begin{tabular}{ccccccc}
\hline Group & Category & No. of Participants & Correct & Percentage & Mean & Standard Deviation \\
\hline \multirow{2}{*}{ Classroom } & Production & 18 & $\begin{array}{c}99 \\
\text { (out of 360) }\end{array}$ & $29.5 \%$ & 5.5000 & 2.47933 \\
\cline { 2 - 6 } & Reception & 18 & $\begin{array}{c}49 \\
(\text { out of 180) }\end{array}$ & $27.22 \%$ & 2.7222 & 1.44733 \\
\hline \multirow{2}{*}{ Naturalistic } & Production & 18 & $\begin{array}{c}213 \\
\text { (out of 360) }\end{array}$ & $59.16 \%$ & 11.8333 \\
\cline { 2 - 6 } & Reception & 18 & $\begin{array}{c}83 \\
(\text { out of 180) }\end{array}$ & $46.11 \%$ & 4.6111 & 2.76828 \\
\hline
\end{tabular}

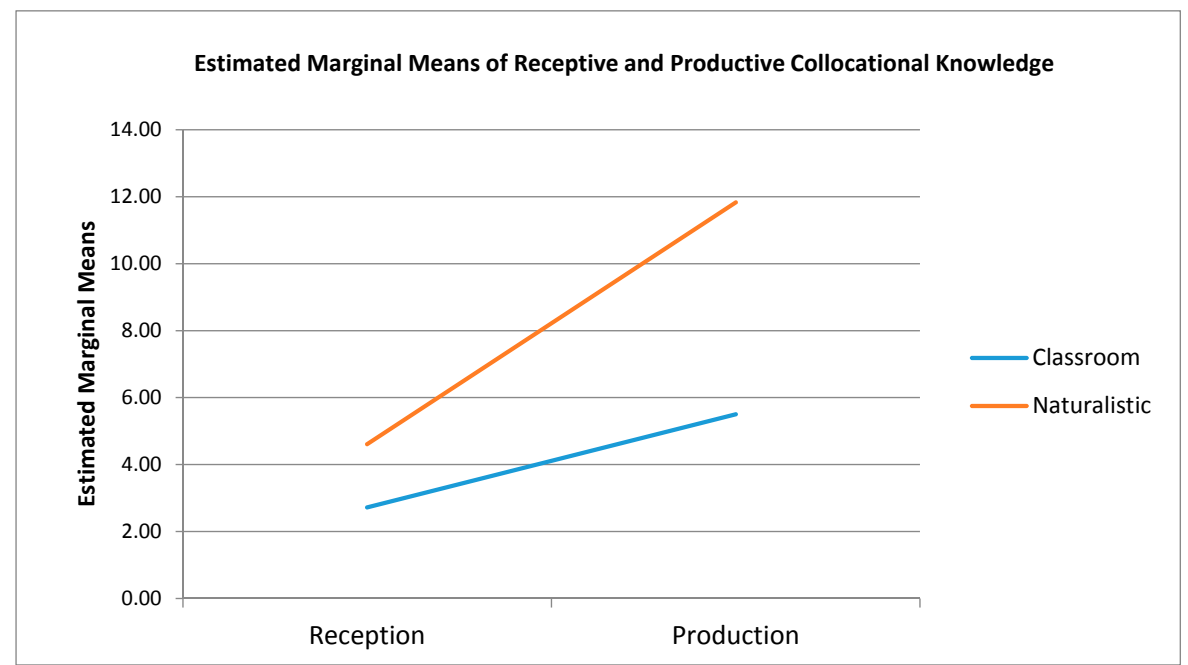

Figure 1. The Receptive and Productive Knowledge of Collocation for the Two Groups.

\subsubsection{The Role of the Learner's L1}

Two assumptions were made about L1 influence. The first was that congruent collocations would pose fewer problems for participants than non-congruent collocations, and therefore, learners would get most of them correct. The second was that L1 influence would be more problematic for classroom learners. To address the first assumption, participants' answers on congruent and non-congruent collocations were compared, and the descriptive statistics of the results are reported in Table 4 below.

Table 4. Mean Scores of Participants' Correct Answers on Congruent and Non-Congruent Collocations for the Two Groups.

\begin{tabular}{cccccc}
\hline Group & Category & Correct Answers & Percentage & Mean & Standard Deviation \\
\hline \multirow{2}{*}{ Classroom } & Congruent & $\begin{array}{c}57 \\
\text { (out of } 162)\end{array}$ & $35.1 \%$ & 3.1667 & 1.38267 \\
\cline { 2 - 6 } & Non-congruent & $\begin{array}{c}42 \\
\text { (out of } 198)\end{array}$ & $21.2 \%$ & 2.3333 & 2.00000 \\
\hline \multirow{2}{*}{ Naturalistic } & Congruent & $\begin{array}{c}116 \\
\text { (out of } 162)\end{array}$ & $71.6 \%$ & 6.4444 & 1.94701 \\
\cline { 2 - 6 } & Non-congruent & $\begin{array}{c}83 \\
\text { (out of } 180)\end{array}$ & $48.9 \%$ & 5.3889 & 3.38055 \\
\hline
\end{tabular}


This shows that the number correct answers for the congruent collocations was slightly higher than that for non-congruent collocations for the classroom group, and reasonably higher for the naturalistic group. The results of a mixed ANOVA test also indicated that there was a significant main effect of congruence on participants' knowledge of collocations $(F(1.00,34)=4.308, p<0.05)$. The direction of this effect was more positive towards congruent collocations, as determined by marginal estimated means of congruent and non-congruent collocations (shown in Figure 2).

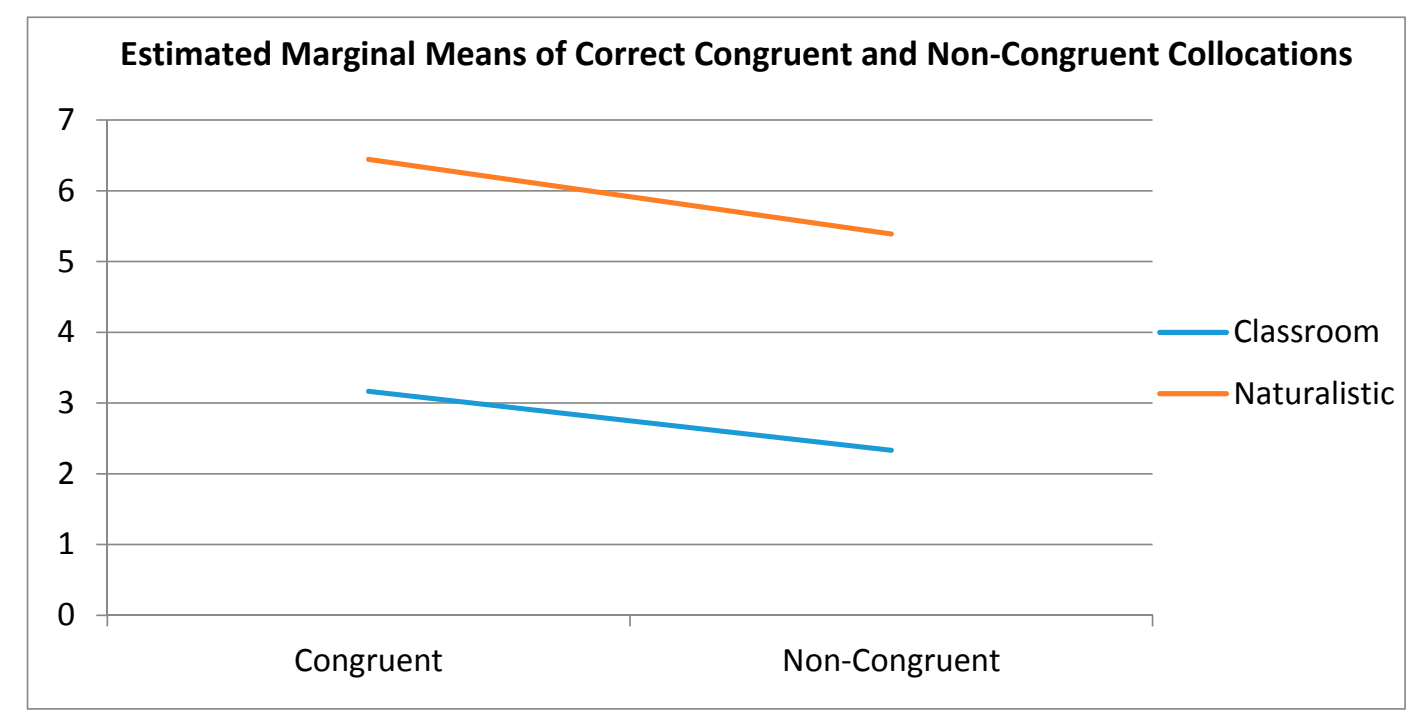

Figure 2. The Correct Answers of Classroom and Naturalistic Groups on Congruent and Non- Congruent Collocations.

As shown above, the number of correct congruent collocations indicates that L1 had a more positive influence on the naturalistic learners' answers than on the classroom learners' answers. To examine the problematic influence of L1, the learners' errors on congruent and non-congruent collocations were analysed using Blum and Levenston (1978) universal principles of lexical simplification, in which learners are claimed to adopt one of these strategies when facing collocation problems: synonymy, transfer, avoidance, or paraphrasing. Two columns were added to account for errors that did not fit into the abovementioned strategies. Table 5 summaries the error analysis of each group, where the negative influence of L1 is represented by "transfer" category.

Table 5. Error Analysis of Classroom Group and Naturalistic Group on Congruent and Non-Congruent Collocations.

\begin{tabular}{cccc}
\hline Type of Errors & Classroom (\%) & Naturalistic (\%) & Examples \\
\hline Synonymy & $73(27.9 \%)$ & $32(21.7 \%)$ & *swift healing (swift recovery) \\
Transfer & $69(26.4 \%)$ & $23(15.6 \%)$ & *execution punishment (capital punishment) \\
Avoidance & $14(5.3 \%)$ & $5(3.4 \%)$ & *great drinker (heavy drinker) \\
Paraphrasing & $14(5.3 \%)$ & $3(2.0 \%)$ & *drinks too much (heavy drinker) \\
Other & $38(14.5 \%)$ & $52(35.3 \%)$ & *be weight (gain weight) \\
Left Blank & $53(20.3 \%)$ & $32(21.7)$ & N/A \\
Error Total & $\mathbf{2 6 1}$ & $\mathbf{1 4 7}$ & \\
\hline \multicolumn{4}{c}{ An asterisk $\left(^{*}\right)$ is used to mark unacceptable collocations. }
\end{tabular}

Therefore, L1 transfer was reported to be higher in the classroom learners' errors than in the naturalistic learners' errors. Furthermore, synonymy was found to be the most adopted strategy by the two groups. This will be discussed further below. 


\subsection{Role of Exposure}

Since it was not possible to control the learner's amount of exposure to L2 and test its impact on L2 collocational knowledge, a questionnaire was used to elicit an estimated amount of informal, naturalistic exposure to English to check if this had any effect on a participant's performance. The Pearson Bivariate correlation test, a test which measures the strength of association between two variables, was then applied to test our formulated hypothesis, to determine whether there was a positive correlation between the learner's amount of exposure to informal, naturalistic English and their productive and receptive knowledge of English collocations (see Table 6).

Table 6. Pearson Bivariate Correlation Test for the Relationship between Hours of Exposure to Informal, Naturalistic English and the Productive and Receptive Knowledge of Collocation.

\begin{tabular}{ccccc}
\hline & & Exposure & Productive & Receptive \\
\hline \multirow{3}{*}{ Exposure } & Pearson Correlation & 1 & $0.770^{* *}$ & $0.722^{* *}$ \\
& Sig. (1-tailed) & & 0.000 & 0.000 \\
& $\mathrm{~N}$ & 36 & 36 & 36 \\
\hline \multirow{3}{*}{ Productive } & Pearson Correlation & $0.770^{* *}$ & 1 & $0.784^{* *}$ \\
& Sig. (1-tailed) & 0.000 & & 0.000 \\
& $\mathrm{~N}$ & 36 & 36 & 36 \\
\hline \multirow{3}{*}{ Receptive } & Pearson Correlation & $0.722^{* *}$ & $0.784^{* *}$ & 1 \\
& Sig. (1-tailed) & 0.000 & 0.000 & \\
& $\mathrm{~N}$ & 36 & 36 & 36 \\
\hline
\end{tabular}

**: correlation is significant at the 0.01 level.

As expected, the number of hours that learners had been informally exposed to naturalistic English strongly correlated with their productive knowledge $(r=0.770, p<0.001)$ and their receptive knowledge $(r=0.722, p<0.001)$ of English collocations. However, this correlation should not be interpreted as causality, since many other factors might have contributed to the development of this knowledge.

\section{Discussion}

Broadly speaking, the results of this study confirmed that $\mathrm{L} 2$ collocations are a problematic aspect of language knowledge for all L2 learners, as the performances of both groups were still far from native-like $(59.2 \%$ and $46.1 \%$ for the naturalistic group and $29.5 \%$ and $27.2 \%$ for the classroom group on productive and receptive collocational knowledge, respectively). This difficulty with collocations could be partially due to the arbitrary nature of word combinations, and also due to the deficiency of grammatical rules in predicting appropriate combinations (Lewis 2002). However, the degree of difficulty did appear differ among individuals and groups. In terms of the latter, formal classroom learners were found to have much poorer receptive and productive knowledge of collocations than informal naturalistic learners. This finding is in agreement with Farghal and Obiedat (1995) and Hussein (1990), who both reported poor knowledge of collocations for instruction-only learners. The naturalistic group, however, showed better productive and receptive knowledge of English collocations with some differences in the level of individual performance; some participants revealed an almost native-like collocational knowledge, whereas others illustrated very poor knowledge of English collocations (see Table 2).

However, one unanticipated finding was that the two groups of learners illustrated better productive than receptive knowledge of English collocations. Following Bahns and Eldaw (1993); Biskup (1990); and Marton (1977), who claimed that learners comprehend more than they are able to produce, we assumed that judging the acceptability of given collocations would be much easier for learners than asking them to produce the missing collocates. However, this assumption was not supported by the results, as learners were shown to have better productive collocational knowledge. However, observation of the participants while conducting the tests showed that some of the difficulties 
with the acceptability test were because it was not clear to the participants what they were supposed to judge, despite being given an example in the test; therefore, a number of learners ended up commenting on aspects of language other than collocations. Unlike the results of accuracy order studies, such as that of Pica (1983), who found no significant effect of learning environment on the acquisition of accuracy order, the learning environment does make a difference with regard to collocation development. The direction of this difference, unlike grammatical studies, such as Krashen et al. (1978) who claimed classroom instruction is more effective than naturalistic exposure, is positively oriented towards a naturalistic learning environment with regard to lexical (collocational) development.

In addition to the overall results, the performance of individual participants did show some variation. For example, participants 1,2,3 and 4 (see Table 2) of the informal naturalistic group showed very good productive and receptive collocational knowledge, even with collocations unfamiliar to most of the other participants, such as rotten eggs and pay a visit. A look at their elicited demographic information, however, revealed that participant 1 has been living in the UK for 10 years and working in a place where interactions with native speakers occur on a daily basis. This participant had never studied English formally abroad, but demonstrated an almost native-like competence on the two tests which, in turn, supports Schmitt (2008, p. 337) claim that "extended stays in an L2-speaking environment lead to a more native like idiomaticity". Participants 2, 3 and 4, on the other hand are medical students who have been living in the native environment for six years, and who had been taught medicine in their home country in English for seven years. Interestingly, even though those participants had not studied English rules formally, either in their countries (apart from being a single module at schools) or in the native country, they performed reasonably well on the two tests, particularly when comparing their scores with final year university students who are specialists in language and who had learnt English only through formal classroom instruction for at least seven years as their major. Thus, similar to Nesselhauf (2005) findings, the "massive" unconscious exposure to L2 does seem to improve collocational knowledge; this was also confirmed in the correlation test.

Further support for the role of informal exposure to the target language is drawn from participant 1 from the classroom group, who illustrated not only the best productive and receptive knowledge of collocations in the group, but also some hours of informal exposure to English outside the classroom through listening to and watching English programmes, and participant 18 from the naturalistic group, who reported the worst performance but also the shortest period of residence in the UK (two years). It could also be that the latter participant found the naturalistic input difficult to understand (more than $i+1$ ) and hence, could not retain collocations from input. In general, however, unlike Bahns and Sibilis (1992) and Marton (1977) who claimed that mere naturalistic exposure to L2 has no impact on collocation learning, this study indicates that increased informal, naturalistic exposure to L2 does help with the development of collocational knowledge.

Such observations agree with Schmitt's claim that collocations can be learnt through "massive" exposure (Schmitt 2008), whilst contrasting Wray (2002) claim for the incapability of adult L2 learners to retain collocations from the exposed input. If Wray (2002) model was taken as correct, then this implies that any deficiencies in the L2 knowledge of collocations is due to an inadequate learning approach, since learners are driven towards a non-formulaic learning approach, rather than due to a lack of collocations in input or lack of exposure to comprehensible input (Durrant and Schmitt 2010). However, this may not be acceptable in light of the results of this study, since, if adult L2 learners are driven towards individual word learning, then this does not explain how the naturalistic learners reached their current collocational knowledge level without being taught collocations formally in classrooms. Even it is true that those learners must have known some English before travelling to the UK, being non-English majors with no classroom learning experiences does not make it likely that they would have had good collocational knowledge before being in the naturalistic environment, particularly if this is considered in comparison to the current poor collocation knowledge of classroom learners. In other words, if classroom learners were found to have poor collocational knowledge despite being English major students for seven years, then it is reasonable to argue that naturalistic 
learners must have developed most, if not all, of their current collocational knowledge whilst being in the native naturalistic environment. Accordingly, and based on the naturalistic group's findings, this study has shown that collocations can be learnt implicitly through informal, naturalistic exposure to L2 for a sufficient period. Deciding this period is not straightforward as this depends on several factors, including the cognitive capacity of the individual learners, the amount and period of contact with L2, and many other factors which could be further investigated.

However, Durrant and Schmitt (2010) offer a more plausible explanation than Wray (2002) as to why learners sometimes fail to acquire collocations, despite being present in input. They argue that learning collocations involves retaining a memory trace of any particular word pair encountered until that pair is encountered again. However, "the relatively sparse nature of most second language input will mean that the extended time which elapses between two exposures to a collocation is usually too long and that trace will be lost, with the result that learning of any but the most frequent collocations can never properly get off the ground" (Durrant and Schmitt 2010, pp. 169-70). So for them, the frequency of the target feature in the input and the period between the two encounters of the same feature are two strong contributory factors for collocation mastering.

Nevertheless, it was not feasible in this study to control the learners' inputs and compare them to their performances. Even results from previous lab-based experiments, such as Durrant and Schmitt (2010), might be questioned, since it is difficult to eliminate any possibilities of knowing some of the collocations being tested before the experiment, and also to eliminate any short-memory impacts.

Nevertheless, our results show that informal, naturalistic learning does improve collocational knowledge, given that the performance of the naturalistic learners was almost double that of the classroom learners. However, since the nature of classroom input was unknown to the researcher (e.g., explicit or implicit) with regard to collocation teaching, our findings cannot be interpreted as classroom instruction being ineffective for collocation learning, but rather that collocations can be developed incidentally through extensive informal, naturalistic exposure to L2. As a whole, the findings did show a significant influence of the learning environment on collocational knowledge, which, in turn, supports the first hypothesis that naturalistic learners have better knowledge of L2 collocations.

In terms of L1 influence, this study has shown that the learner's L1 did affect the knowledge of English collocations. However, the nature and the degree of that effect differed among the groups. L1 had a more positive influence on the answers of the naturalistic learners than the classroom learners, as indicated by the number of correct congruent collocations (see Table 4). Conversely, L1 negatively influenced the performance of the classroom group more than the performance of the naturalistic group, as indicated by the transfer percentages in Table 5 . However, analysing the types of errors produced by the two groups (naturalistic vs. classroom) gave us more insight into how L1 had negatively affected the participants' results. In doing so, the universal principles of lexical simplification (Bonk 2000) were adopted for error analysis.

The strategies considered here are those adopted by Farghal and Obiedat (1995) of synonymy, transfer, avoidance, and paraphrasing, as discussed earlier. Synonymy refers to instances where learners rely on their vocabulary knowledge by choosing the available synonyms that can semantically fit into the target collocation (e.g., "swift healing/curing for swift recovery, and *increase/acquire/obtain weight for gain weight), without realising the degree of combinability of those lexical items in that particular sentence.

The heavy use of this strategy (27.9\% for classroom group (CRG) and $21.7 \%$ for Naturalistic group (NG)) is believed to be a result of collocation unawareness, since the data obtained showed that learners were unaware that some combinations are "neither freely combinable nor largely opaque and fixed (such as idioms) but that are nevertheless arbitrary to some degree and therefore have to be learnt" (Nesselhauf 2005, p. 252). This unawareness was evident when the participants' answers on the production and reception tests were compared to their VRT answers. For example, despite nearly all of the participants (both groups) reporting knowledge of the meaning of verbs such as have, make, 
and do, some participants produced deviant collocations such as *create friends (instead of make friends), and incorrectly judged collocations such as *do an effort (instead of make an effort) as acceptable. So, even for the lexical items that are more commonly known to the learners, the combinability of those items was still challenging for them. However, there were also cases (e.g., *rancid eggs) where resorting to synonymy strategy was due to lack of word knowledge (as rotten was not underlined in VRT). Therefore, and similar to Granger (1998); Hussein (1990); and Nesselhauf (2005), the results indicated that the interference from the learner's mother tongue and the lack of awareness of collocations was a major source of the errors made in the tests. This problem was more evident with Arab learners, most likely because "they are not being made aware of collocations as a fundamental genre of multi-word units" (Farghal and Obiedat 1995, p. 326).

Transfer, however, occurs when learners hypothesise that there is a direct correspondence between L1 and L2; hence, they rely on their L1 while filling in the missing collocates (Farghal and Obiedat 1995). However, this working hypothesis correctly produced some collocations (e.g., white lie-congruent collocations) in instances where the two lexical items had the same Arabic equivalents, but also produced many deviant collocations when one or both of the lexical items did not have an Arabic equivalent (e.g., *heavy tea instead of strong tea-non-congruent category). Thus, unlike Farghal and Obiedat (1995), who found a weak influence of L1 on the learners' errors (9.9\% for group A and $12.6 \%$ for group B), the influence of L1 in this study was higher, as transfer was found to be the second most adopted strategy by both groups $(26.4 \%$ for CRG and $15.6 \%$ for NG). Avoidance and paraphrasing, however, are not of particular focus in here-in brief, the former is involved when the learner avoids the target lexical item in favour of another, yielding a shift in meaning (e.g., great drinker instead of heavy drinker), whereas paraphrasing is the type of strategy involved in drinks too much instead of heavy drinker (Farghal and Obiedat 1995).

With respect to congruent and non-congruent collocations, there were more errors occurring in the latter category than with the former: $46.6 \%$ for congruent collocations and $64.8 \%$ for non-congruent collocations. In terms of the types of errors made, the majority of congruent errors were of synonymy type (e.g., *increase weight instead of gain weight, *create a decision instead of make a decision, and *swift healing instead of swift recovery), whereas most non-congruent errors were of transfer type (e.g., *strong rain instead of heavy rain, *excessive drinker instead of heavy drinker). This finding was unexpected; the assumption was that congruent collocations would not pose problems to the participants as they have equivalent words in Arabic, and therefore, the learners would answer most of these correctly. However, the surprising number of congruent errors could also be a direct result of some shortcomings of the test materials, as some of the congruent collocations (e.g., play role) have an Arabic equivalent and also a few other semantically possible combinations (e.g., تلعب دورا) 'take a role') that perfectly fit in the Arabic translated sentence. This in turn presented two possible combinations for the participants to choose from if they were not aware of the restrictions on the collocability of the lexical items in the target language.

Another problem caused by the selection of test items was that the correctness of some congruent collocations (e.g., enroll on a course) was dependent on the context of the sentence, i.e., having other combinations (such as register on a course or go on a course) in the sentence, It is the first week of registration; Beth's son wants to ......... on a course of some sort but just can't make a decision about what to study, were considered incorrect despite being possible collocations in English. Therefore, if this study was replicated, the choice of congruent collocations would be restricted to those with only one possible equivalent in L1 (such as white lie) and the correctness of congruent collocations would be made independent from the sentence context (as with swift recovery). However, as a whole, congruent collocations posed fewer problems to the learners than non-congruent collocations (as indicated in Table 4 and Figure 2), which accordingly supports the first assumption about L1 influence.

With non-congruent collocations, however, most of the errors were made as a result of L1 transfer as in *heavy tea instead of strong tea and *strong rain instead of heavy rain. While it would be unlikely for 
such learners to be unfamiliar with the individual lexical items of these collocations (which was also confirmed in the VRT), many participants most likely elicited these collocations incorrectly because they were unaware that even though both heavy and strong are semantically related, only one of these lexical items can be correctly combined with tea and rain nouns in Arabic and English, and hence, the interchangeable use of these words could yield violations.

Other errors due to L1 transfer were reported in cases where the verb collocates only with one noun in L1, but a few nouns in L2, where each is restricted to a particular context. For example, given that both commit crime and commit murder are possible combinations in English, most classroom learners and few naturalistic learners elicited commit crime where the context of deliberate killing allows only for commit murder. The participants were potentially de-contexualising the lexical item of the collocations from its context, and they might have then relied on their L1 and L2 vocabulary knowledge while filling in the missing collocate. In Arabic, the verb 'commit' only collocates with the noun 'crime' and not 'murder'. Interestingly, most of the participants reported to know the word murder in the VRT. This type of error was greater in CRG than in NG (as indicated in Table 5), which could be interpreted as L1 having a more negative impact on classroom learners.

Therefore, in contrast with Granger (1998) and Nesselhauf (2005) who state that congruent collocations can be easily translated into L2, and hence, it is the non-congruent collocations that should be taught, our study indicated that both categories of collocations could be potential sources of errors if learners were unaware of collocations. This may, in turn, support the claim that what students really lack is not vocabulary knowledge but collocation awareness, especially as synonymy is the most adopted simplification strategy among the two groups, and as the overall percentage of collocational errors was reasonably high (56.6\% on the production test and $63.3 \%$ on the receptive test), despite the fact that many of the adopted collocations were made of simple everyday vocabulary such as make, do, heavy, rain, etc. Thus, L1 does appear to influence L2 collocational knowledge. This influence had a more positive impact on the naturalistic learners, whereas it had a more negative impact on the classroom learners.

However, there are also limits of this influence, as some scholars (e.g., Nesselhauf 2005) have argued that a learner's performance should be interpreted in the light of intralinguistic factors, such as degree of restriction and congruence in L1 and L2, as well as extralinguistic factors, such as circumstances of production and exposure to L2. This study targeted only a few of those factors, while the others could be included as targets in future research.

\section{Conclusions and Implications}

\subsection{Conclusions}

This study's aim was to investigate the role of the learning environment and the influence of L1 on L2 collocations, by comparing the receptive and productive knowledge of Libyan Arabic-speaking learners of English in formal classroom settings in EFL environment, compared to those in an informal naturalistic setting exposed to English in a native-speaking environment. The study has shown that L2 collocations are a problematic aspect of knowledge for all L2 learners. However, the results of this study have also demonstrated that learners in a naturalistic environment have a more advanced productive and receptive collocational knowledge than those in a classroom environment. It has also been shown that Arabic (as L1of participants) influenced all of the participants' results. The nature of this influence had a more positive impact on the naturalistic learners' answers (indicated by correct congruent collocations), and a more negative impact on the classroom learners' answers (indicated by errors made due to transfer).

The other major finding of the study was the strong correlation between knowledge of English collocations and level of informal exposure to English, whereby it was interpreted from the results that collocations can be learnt implicitly through 'massive informal exposure' to language. Having said this, a comparison between participants' answers on the two tests and their vocabulary recognition 
task made it clear that it was due to a lack of collocation awareness which resulted in a great number of errors.

\subsection{Some Implications for Teaching}

These findings could be beneficial in making some pedagogical decisions on how to teach collocations. Firstly, similar to Nesselhauf who stated that "in most of the recent publications on the teaching of collocations, making learners aware of the phenomenon is considered the foremost task of the teacher" (Nesselhauf 2003, p. 238), this study revealed that most of the errors made by participants were due to unawareness of collocations. Therefore, teachers need to raise their students' awareness of collocations while teaching vocabulary by, instead of using definitional meanings alone when learning new words; making learners aware of the use of those particular words and degree of restriction in their use. In other words, a word's definitional meaning is insufficient for learning how and when to use that word, since two synonyms, such as wound and injury, can share their definitional meaning, but cannot be used interchangeably in their collocational field, e.g., stab wound rather than stab injury whereas internal injuries rather than internal wounds (Lewis 2000, p. 13).

Moreover, this would help learners to think higher than one word level which, in turn, could help them to notice the combinability of lexical items (Hill 2000). Lewis adds that teachers could enhance learners' awareness of collocations by getting them to notice words and their combinability in reading (Lewis 2000). This does not necessarily mean finding rare words, but rather by finding some common words and raising students' attention to them in chunks, by getting them to notice which words go together. Teachers should also push learners to produce what they have noticed, so that when they experience difficulty in expressing what they are trying to say, they will "notice the gap" (Schmidt and Frota 1986) in their collocational knowledge and they will try to bridge this gap during subsequent exposure to its input.

Secondly, since this study made it clear that the learning environment and L2 naturalistic input do help in developing L2 collocations, it might be useful to employ more communicative interactive activities for classroom teaching, since natural input is believed to offer a richer source of collocations than textbooks, where input is manipulated to contain particular features that are meant to be taught. This was further supported by Burger and Gallina (2008, p. 7) who stated that "when students see words in authentic contexts, they learn how the words function and what their typical collocations are".

Thirdly, given that L1 interference was found to be a relevant factor in generating wrong collocations for Libyan Arab learners, L2 learners have to be made aware of the similarities and differences in L1 and L2 collocations in regard to non-congruence in L1 and L2 where relying on L1 is undesirable. Also, non-congruent collocations were found to be more problematic than congruent collocations, and hence, they need more attention in language teaching. However, the claim that congruent collocations can be automatically learnt Nesselhauf (2005) (Bahns 1993) cannot be inferred from our results, since a number of errors were reported on congruent collocations. Thus, further research is needed to determine which category of congruent collocations is the most problematic, and therefore deserves closer attention in language teaching. The suggestions made in this study can only be confirmed by further research, and could be inappropriate for other groups of learners who differ substantially from the sample participants in this study.

Conflicts of Interest: The author declares no conflict of interest.

\section{References}

Allerton, David. 1984. Three or Four Levels of Word Co-occurrence Restriction. Lingua 63: 17-40. [CrossRef] Altenberg, Bengt. 1993. Recurrent Verb-Complement Constructions in the London-Lund Corpus. In English Language Corpora: Design, Analysis and Exploitation. Edited by Jan Aarts, Pieter de Haan and Nelleke Oostdijk. Amsterdam: Rodopi, pp. 227-45. 
Al-Zahrani, Mohammad S. 1998. Knowledge of English Lexical Collocations among Male Saudi College Students Majoring in English at a Saudi University. Ph.D. dissertation, Indiana University of Pennsylvania, Indiana, PA, USA.

Bahns, Jens. 1993. Collocations: A contrastive view. ELT Journal 47: 56-63. [CrossRef]

Bahns, Jens, and Moira Eldaw. 1993. Should We Teach EFL Students Collocations? System 21: 101-14. [CrossRef] Bahns, Jens, and Ulrich Sibilis. 1992. Kollokationslernen Durch Lektüre. Neusprachliche Mitteilungen 45: 158-63.

Baker, Mona. 1992. In Other Words. London: Routledge.

Benson, Morton, Evelyn Benson, and Robert Ilson. 1986. The BBI Combinatory Dictionary of English. Amsterdam: John Benjamins Publishing Company.

Biskup, Danuta. 1990. Some Remarks on Combinability: Lexical collocations. In Foreign Language Acquisition Papers. Edited by Janusz Arabski. Katowice: Uniwersytet Slaski, pp. 31-44.

Biskup, Danuta. 1992. L1 Influence on Learners' Renderings of English Collocations: A Polish/German empirical study. In Vocabulary and Applied Linguistics. Edited by Pierre J. Arnaud and Henri Bejoint. London: Macmillian, pp. 85-93.

Blum, Shoshana, and Eddie Levenston. 1978. Universals of Lexical Simplification. Language Learning 28: $399-415$. [CrossRef]

Bonk, William J. 2000. Testing ESL Learners' Knowledge of collocations. ELT Journal 35: 115-22.

Brown, Dorothy F. 1974. Advanced Vocabulary Teaching: The problem of collocation. RElC Journal 5: 1-11. [CrossRef]

Burger, S., and J. Gallina. 2008. Teaching and Assessing Academic Vocabulary Based on the Academic Word List. Contact 34: 1-80.

Channell, Joanna. 1981. Applying Semantic Theory to Vocabulary Teaching. English Language Teaching Journal 35: 115-22. [CrossRef]

Conklin, Kathy, and Norbert Schmitt. 2007. Formulaic Sequences: Are they processed more quickly than nonformulaic language by native and non-native speakers? Applied Linguistics 29: 72-89. [CrossRef]

Cowie, Anthony P. 1981. The Treatment of Collocations and Idioms in Learners' dictionaries. Applied Linguistics 2: 223-35. [CrossRef]

Cowie, Anthony P. 1988. Stable and Creative Aspects of Vocabulary Use. In Vocabulary and Language Teaching. Edited by Ronald Carter and Michael McCarthy. Harlow: Longman, pp. 126-37.

Cowie, Anthony P. 1994. Phraseology. In The Encyclopedia of Language and Linguistic. Edited by Ron E. Asher. Oxford: Pergamon, pp. 3168-71.

Cowie, Anthony P., and Peter Howarth. 1996. Phraseological Competence and Written Proficiency. In Language and Education. Edited by George M. Blue and Rosamond Mitchell. Clevendon: Multilingual Matters, pp. 80-93.

Dechert, Hans W., and Paul Lennon. 1989. Collocational Blends of Advanced Language Learners: A preliminary analysis. In Contrastive Pragmatics. Edited by Wieslaw Oleksy. Amsterdam: John Benjamin, pp. 131-68.

Durrant, Philip, and Norbert Schmitt. 2010. Adult Learners' Retention of Collocations from Exposure. Second Language Research 26: 163-88. [CrossRef]

Erman, Britt, and Beatrice Warren. 2000. The Idiom Principle and the Open Choice Principle. Text-Interdisciplinary Journal for the Study of Discourse 20: 29-62. [CrossRef]

Farghal, Mohammed, and Hussein Obiedat. 1995. Collocations: A neglected variable in EFL. IRAL 33: 315-31. [CrossRef]

Firth, John Rupert, ed. 1957. Modes of Meaning. In Papers in Linguistics. Oxford: Oxford University Press, pp. 190-215. Granger, Sylviane. 1998. Prefabricated Patterns in Advanced EFL Writing: Collocations and Formulae. In Phraseology: Theory, Analysis, and Applications. Edited by Anthony P. Cowie. Oxford: Oxford University Press, pp. 145-60.

Halliday, Michael A. K. 1966. Lexis as a Linguistic Level. In Memory of J.R. Firth. Edited by Charles Ernest Bazell, John Cunnison Catford, Michael A. K. Halliday and Robert Henry Robins. London: Longmans, pp. 148-62.

Hausmann, Franz Josef. 1989. Le dictionnaire de collocations. In Wörterbücher, Dictionaries, Dictionnaires. Ein Internationales Handbuch zur Lexicographie. Edited by Rufus Gouws, Ulrich Heid, Wolfgang Schweickard and Herbert Ernst Wiegand. Berlin: de Gruyter, pp. 1010-19.

Herbst, Thomas. 1996. What are Collocations: Sandy beaches or false teeth? English Studies 77: 379-93. [CrossRef]

Hill, Jimmie. 2000. Revising Priorities: From grammatical failure to collocational success. In Teaching Collocation. Edited by Michael Lewis. Hove and London: Language Teaching Publications, pp. 28-46.

Hoey, Michael. 2005. Lexical Priming: A New Theory of Words and Language. London: Routledge.

Howarth, Peter. 1998. Phraseology and Second language Proficiency. Applied linguistics 19: 45-72. [CrossRef] 
Huang, Li-Szu. 2001. Knowledge of English Collocations: An analysis of Taiwanese EFL learners. In Texas Papers in Foreign Language Education: Selected Proceedings from the Texas Foreign Language Education Conference. Edited by Christopher Luke and Brian Rubrecht. Austin: Texas University, pp. 113-32.

Hunston, Hunston, and Gill Francis. 2000. Pattern Grammar: A Corpus-Driven Approach to the Lexical Grammar of English. Amsterdam: John Benjamins.

Hussein, Riyad Fayez. 1990. Collocations: The missing link in vocabulary acquisition amongst EFL learners. Papers and Studies in Contrastive Linguistics 26: 123-36.

Hymes, Dell H. 1972. On Communicative Competence. Philadelphia: University of Pennsylvania Press.

Krashen, Stephen. 1976. Formal and Informal Linguistic Environments in Language Learning and Language Acquisition. TESOL Quarterly 10: 157-68. [CrossRef]

Krashen, Stephen. 1985. The Input Hypothesis. London: Longman.

Krashen, Stephen D., and Herbert W. Seliger. 1975. The Essential Contributions of Formal Instruction in Adult Second Language Learning. TESOL Quarterly 9: 173-83. [CrossRef]

Krashen, Stephen D., Victoria Sferlazza, Lorna Feldman, and Ann Fathman. 1976. Adult Performance on the SLOPE test: More evidence for a natural sequence in adult second language acquisition. Language Learning 26: 145-51. [CrossRef]

Krashen, Stephen, S. Jones, Stanley J. Zelinski, and C. Usprich. 1978. How Important is English Language Instruction? English Language Teaching Journal 32: 257-60. [CrossRef]

Laufer, Batia. 1990. Why are Some Words more Difficult than Others? Some intralexical factors that affect the learning of words. IRAL 28: 293-307. [CrossRef]

Lennon, Paul. 1996. Getting 'Easy' Verbs Wrong at the Advanced Level. IRAL 34: 23-36. [CrossRef]

Lewis, Michael. 1993. The Lexical Approach: The State of ELT and a Way Forward. London: Thomson Heinle.

Lewis, Michael. 1997. Implementing the Lexical Approach: Putting Theory into Practice. Hove: LTP.

Lewis, Michael. 2000. Learning in the Lexical Approach. In Teaching Collocation: Further Development in the Lexical Approach. Edited by Michael Lewis. Hove: Language Teaching Publications, pp. 155-84.

Lewis, Michael. 2002. Implementing the Lexical Approach. Putting Theory into Practice. Boston: Thomson Heinle.

Mahmoud, Abdulmoneim. 2005. Collocation Errors Made by Arab Learners of English. Asian EFL Journal 6: 117-26.

Marton, Donna M. 1977. Research Methods in Education and Psychology: Integrating Diversity with Quantitative $\mathcal{E}$ Qualitative Approaches. Thousand Oaks: Sage Publications, Inc.

Martynska, Małgorzata. 2004. Do English Language Learners know Collocations? Investigations Linguisticae 11: 1-12. [CrossRef]

McCarthy, Michael. 1990. Vocabulary. Oxford: Oxford University Press.

McCarthy, Michael, and Felicity O'Dell. 2005. English Collocations in Use. Cambridge: Cambridge University Press.

Mel'čuk, Igor. 1998. Collocations and Lexical Functions. In Phraseology: Theory, Analysis, and Applications. Edited by Anthony P. Cowie. Oxford: Clarendon, pp. 23-53.

Mochizuki, Masamichi. 2002. Exploration of Two Aspects of Vocabulary Knowledge: Paradigmatic and Collocational. Annual Review of English Language Education in Japan 13: 121-29.

Morra, Sergio, and Roberta Camba. 2009. Vocabulary Learning in Primary School Children: Working memory and long-term memory components. Journal of Experimental Child Psychology 104: 156-78. [CrossRef] [PubMed]

Nation, Ian S. P. 2001. Learning Vocabulary in Another Language. Cambridge: Cambridge University Press.

Nattinger, James R., and Jeanette S. Decarrico. 1992. Lexical Phrases and Language Teaching. Oxford: Oxford University Press.

Nesselhauf, Nadja. 2003. The Use of Collocations by Advanced Learners of English and some Implications for Teaching. Applied Linguistics 24: 223-42. [CrossRef]

Nesselhauf, Nadja. 2005. Collocations in a Learner Corpus. Amsterdam: Benjamins.

Pawley, Andrew, and Frances Hodgetts Syder. 1983. Two Puzzles for Linguistic Theory: Nativelike selection and nativelike fluency. In Language and Communication. Edited by Jack C. Richards and Richard W. Schmidt. New York: Longman, pp. 191-225.

Perkins, Kyle, and Diane Larsen-Freeman. 1975. The Effect of Formal Instruction on the Order of Morpheme Acquisition. Language Learning 25: 237-43. [CrossRef]

Pica, Teresa. 1983. Adult Acquisition of English as a Second Language under Different Conditions of Exposure. Language Learning 33: 465-97. [CrossRef]

Richards, Jack C. 1976. The Role of Vocabulary Teaching. TESOL Quarterly 10: 77-89. [CrossRef] 
Schmidt, Richard, and Sylvia Frota. 1986. Developing Basic Conversational Ability in a Second Language: A case study of an adult learner of Portuguese. In Talking to Learn: Conversation in Second Language Acquisition. Edited by Richard R. Day. Rowley: Newbury House, pp. 237-326.

Schmitt, Norbert. 2000. Vocabulary in Language Teaching. Cambridge: Cambridge University Press.

Schmitt, Norbert. 2004. Formulaic Sequences: Acquisition, Processing and Use. Amsterdam: John Benjamins.

Schmitt, Norbert. 2008. Instructed Second Language Vocabulary Learning. Language Teaching Research 12: 329-63. [CrossRef]

Shehata, Asmaa. 2008. L1 Influence on the Reception and Production of Collocations by Advanced ESL/EFL Arabic Learners of English. Master's thesis, The College of Arts and Sciences of Ohio University, Athens, $\mathrm{OH}$, USA.

Sinclair, John M. 1966. Beginning the Study of Lexis. In Memory of J.R. Firth. Edited by Charles Ernest Bazell, John Cunnison Catford, Michael A. K. Halliday and Robert Henry Robins. London: Longmans, pp. 410-30. Sinclair, John M. 1991. Corpus, Concordance, Collocation. Oxford: Oxford University Press.

Siyanova, Anna, and Norbert Schmitt. 2008. L2 Learner Production and Processing of Collocation: A multi-study perspective. Canadian Modern Language Review—Revue Canadienne Des Langues Vivantes 64: 429-58. [CrossRef]

Turner, Dow. 1979. The Effect of Instruction on Second Language Learning and Second Language Acquisition. In The Acquisition and Use of Spanish and English as First and Second Languages. Edited by Roger W. Andersen. Washington: TESOL.

Vasiljevic, Zorana. 2008. Teaching Vocabulary to Advanced Japanese Students: A word association approach. The East Asian Learner 4: 1-19.

Wilkins, David Arthur. 1972. Linguistics in Language Teaching. London: Edward Arnold.

Willis, Dave. 1990. The Lexical Syllabus. London: Collins.

Wray, Alison. 2002. Formulaic Language and the Lexicon. Cambridge: Cambridge University Press.

Zhang, Xiaolin. 1993. English Collocations and Their Effect on the Writing of Native and Non-Native College Freshmen. Ann Arbor: UMI.

Zughoul, Muhammad Raji. 1991. Lexical Choice: Towards writing problematic word lists. International Review of Applied Linguistics 29: 45-58.

(C) 2018 by the author. Licensee MDPI, Basel, Switzerland. This article is an open access article distributed under the terms and conditions of the Creative Commons Attribution (CC BY) license (http:/ / creativecommons.org/licenses/by/4.0/). 